\title{
Thyroid Function in Molar Pregnancies
}

\author{
Sinha $\mathrm{K}^{1}$, Das $\mathrm{R}^{1}$, Adhikari $\mathrm{H}^{1}$
}

\begin{abstract}
Introduction: Molar pregnancies represent a significant burden of disease on the spectrum of gestational trophoblastic diseases. Vaginal bleeding being the most common occasionally, molar pregnancy is complicated by hyperthyroidism, which may require treatment. Aims: To determine thyroid function test and association of hyperthyroidism among the cases of molar pregnancy. Methods: This is a hospital-based cross-sectional study conducted in the department of Obstetrics and Gynecology, Nepalgunj Medical College and Teaching Hospital, Kohalpur. Sixty cases of molar pregnancy were included during the study period from February 2020 to January 2021.Patients having history of known thyroid disorders were excluded. Results: Prevalence of molar pregnancy in our study was 5.4 per thousand pregnancies in our hospital. Molar pregnancy and hyperthyroidism, both were common in the age group of 21-35 years. Hyperthyroidism was present in $10 \%$ patients. Enlarged thyroid was seen in $3.3 \%$, tremor was present in $3.3 \%$, and palpitation in $21.5 \%$. Five (8.3\%) patients with hyperthyroidism were underweight. Majority of patients with hyperthyroidism, beta humanchorionic gonadotrophhin level was more than three lakhs and it was mostly associated with complete hydatidiform mole compared to partial hydatidiform mole. Thyroid storm was not experienced in any of the patients. Conclusion: The rate of molar pregnancy is high. Hyperthyroidism in molar pregnancy is not uncommon. High levels of human chorionic gonadotropin, complete hydatiform mole are directly associated with hyperthyroidism. Awareness of this condition is important for diagnosis and treatment to prevent life threatening complications.
\end{abstract}

Keywords: Beta human chorionic gonadotropin, Gestational trophoblastic disease, Hyperthyroidism, Molar pregnancy

Authors:

1. Dr. Kavita Sinha

2. Dr. Ram Das

3. Dr. Homnath Adhikari

${ }^{1}$ Department of Obst. \&Gynaecology, Nepalgunj Medical College and Teaching Hospital, Kohalpur, Banke

\section{Address for Correspondence:}

Dr. Kavita Sinha

Department of Obstetrics and Gynaecology

Nepalgunj Medical College and Teaching Hospital

Kohalpur, Banke

Email: ksinhapandey@gmail.com

\section{INTRODUCTION}

Gestational trophoblastic disease includes a series of disorders that are characterized by an abnormal proliferation of trophoblastic tissue with varying tendency to spontaneous remission, local invasion and metastasis. ${ }^{1}$ Hydatidiform mole refers to an abnormal pregnancy characterized by varying degrees of trophoblastic proliferation and vesicular swelling of placental villi associated with an absent or an abnormal fetus. It exists in two distinct forms, complete hydatidiform mole (CHM) and partial hydatidiform mole (PHM). ${ }^{2}$ According to studies in Nepal prevalence ranges from 2.8 to 5.1 per thousand live births. ${ }^{3}$ The 5 -year prevalence of molar pregnancy at B.P. Koirala Institute of Health Sciences during the study period of 2008-2012 was 4.17 per 1000 live births. ${ }^{4}$

The pathophysiology of hyperthyroidism in GTD is wellinvestigated. Placental trophoblastic tissue secretes excessive hCG, with two sub units the $\alpha$ and $\beta$. The $\alpha$ subunit which is structurally similar to thyroid stimulating hormone and also has enhanced thyrotropic activity. It can be definitively managed with surgical evacuation of the uterus; severe complications associated with hyperthyroidism in GTD have been reported. ${ }^{5}$ Vigilant monitoring and intensive care should be extended into the postoperative period. ${ }^{6}$ Follow-up after evacuation of a hydatidiform mole is essential. Due to undetected hyperthyroidism, the patient may develop tachycardia, arrhythmias, hyperthermia, pulmonary hypertension and cardiac failure and can even progress to a life-threatening thyroid storm. ${ }^{7}$ It is therefore important to check thyroid levels in every patient with molar pregnancy. Hence this study is conducted in order to anticipate and manage the complications that may arise.

\section{METHODS}

The cross sectional study was carried out on the patients attending outpatient department or admitted to Department 
of Obstetrics and Gynecology, Nepalgunj Medical College, Kohalpur, from February 2020 to January 2021, for a period of one year. Ethical clearance was obtained from the Institutional Review Committee, Nepalgunj Medical College, Teaching Hospital and written informed consent wastaken from each patient. The thyroid profile was performed on all cases to see the association of thyrotoxicosis with molar pregnancy. Study included 60 patients of molar pregnancy. Selection of caseswas done by convenient sampling method.

All cases of hydatidiform mole diagnosed by ultrasonography or histopathologically were included in this study while known cases of thyroid disorder were excluded. Data was collected on a structured proforma. The participants were enquired about demographic factors: maternal age, socioeconomic status, occupation, detail obstetrics history including LMP, EDD, period of gestation of present pregnancy, parity, past obstetrics performance and outcomes including previous abortions, previous history of molar pregnancies were studied. A detailed history regarding the signs and symptoms of thyroid disorder, past medical and surgical history was taken. In the present molar pregnancy, complications like hypertensive disorders (Preeclampsia and Eclampsia), anemia (<11gm/ $\mathrm{dl} \mathrm{Hb}$ ), tachycardia, hyperthyroidism, enlarged thyroid were noted. General and systemic examination was carried out in all patients. Their blood pressure, temperature, pulse and Body Mass Index (according to the national institute of health, 2000) were recorded. Local thyroid examinations, per abdominal examination and per vaginal examination were

performed. Blood samples collected for investigations which included $\mathrm{Hb} \%$, blood grouping and Rh typing, thyroid function test, serum beta-hCG. Urine samples collected for albumin, sugar and microscopy.

TFT were assayed using standard and sensitive chemiluminence immunoassay (CLIA) method by using LUMAX-CLIA stripe reader. Depending upon the level of fT3, fT4 and TSH patient were diagnosed as euthyroid, hyperthyroid or hypothyroid. ${ }^{18}$ As a primary mode of management suction and evacuation done for all patients. Whole of the samples obtained sent for histopathological examination. The serum beta HCG was repeated 48 hours after evacuation. Patient was followed up for normalization of beta HCG and histopathology report. Results are presented as number and percentage for corresponding each group. Chi-square test was used for the analysis of data. $P$ value was considered significant if it was less than 0.05 .

\section{RESULTS}

Total number of patients with molar pregnancy during the study period was 60 . The prevalence of molar pregnancy in our hospital was found to be 5.4per thousands of total pregnancy (5975) in one year.

\begin{tabular}{|lcc|}
\hline Parameters & $\begin{array}{c}\text { Normal } \\
(\mathbf{n}=54) 90 \%\end{array}$ & $\begin{array}{c}\text { Hyperthyroid } \\
(\mathbf{n}=6) 10 \%\end{array}$ \\
\hline $\mathrm{fT} 3(\mathrm{nmol} / \mathrm{L})$ & $3.427 \pm 0.768$ & $8.382 \pm 1.215$ \\
\hline $\mathrm{fT} 4(\mathrm{nmol} / \mathrm{L})$ & $1.378 \pm 0.35$ & $2.513 \pm 1.478$ \\
\hline $\mathrm{TSH}(\mathrm{mlU} / \mathrm{L})$ & $1.971 \pm 1.462$ & $0.107 \pm 0.107$ \\
\hline
\end{tabular}

Table l: Thyroid function test in study group

In patients with hyperthyroidism the mean $\mathrm{fT} 3(\mathrm{nmol} / \mathrm{L})$ was $8.32 \pm 1.2$, fT4 $(\mathrm{nmol} / \mathrm{L})$ was $2.513 \pm 1.478$ and TSH (mIU/L) $0.107 \pm 0.107$ (Table I).

\begin{tabular}{|lccc|}
\hline \multicolumn{1}{|c}{ Clinical characteristics } & CHM & PHM & p-value \\
\hline Maternal age (in years) & $25.61 \pm 7.78$ & $21.29 \pm 2.62$ & 0.075 \\
\hline $\begin{array}{l}\text { Gestational age (in weeks) } \\
\text { Pre evacuation beta hCG (in } \\
\text { lakhs IU/L) }\end{array}$ & $14.45 \pm 2.89$ & $14.86 \pm 1.95$ & 0.115 \\
\hline fT3(nmol/L) & $3.91 \pm 1.67$ & $3.211 \pm 0.535$ & 0.171 \\
\hline fT4(nmol/L) & $1.41 \pm 0.52$ & $1.54 \pm 0.422$ & 0.97 \\
\hline TSH (mIU/L) & $1.78 \pm 1.50$ & $1.530 \pm 1.533$ & 0.594 \\
\hline Hyperthyroid State & $6(10 \%)$ & 0 & 0.039 \\
\hline
\end{tabular}

*CHM: Complete Hydatiform Mole, PHM: Partial Hydatiform Mole

\section{Table II: Comparison between CHM and PHM $(n=60)$}

Clinical characteristics were compared between patients of complete mole and partial mole (Table II). Maternal age higher in CHM and the difference was statistically significant. There was no difference in the gestational age at presentation between the two groups. Though the pre evacuation beta hCG levels were higher in CHM patients compared to PHM, it was not statistically significant. All $6(10 \%)$ with $\mathrm{CHM}$ were hyperthyroid. Mean values of thyroid hormones in complete and partial moles were compared and the difference was not statistically significant.

\begin{tabular}{ccccc}
$\begin{array}{c}\text { Age of patient } \\
\text { (Years) }\end{array}$ & \multicolumn{2}{c}{ Hyperthyroidism } & Total & p-value \\
& Present & Absent & & \\
$<20$ & 1 & 19 & 20 & \\
& $(1.7 \%)$ & $(31.7 \%)$ & $(33.3 \%)$ & \\
$21-35$ & 3 & 33 & 36 & 0.02 \\
& $(5.0 \%)$ & $(55.0 \%)$ & $(60 \%)$ & \\
$>35$ & 2 & 2 & 4 & \\
& $(3.3 \%)$ & $(3.3 \%)$ & $(6.7 \%)$ & \\
Total & 6 & $\mathbf{5 4}$ & $\mathbf{6 0}$ & \\
& $(\mathbf{1 0 \% )}$ & $(\mathbf{9 0 \% )}$ & $(\mathbf{1 0 0 \% )}$ &
\end{tabular}

Table III: Association of maternal age with hyperthyroidism ( $n=60)$

The hyperthyroidism was common in the age group of 21-35. 
The difference was statistically significant (Table III).

\begin{tabular}{lcc|} 
Symptoms & Frequency & Hyperthyroidism \\
\hline Enlarged thyroid & 2 & 1 \\
\hline Tremor & $(3.3 \%)$ & $(1.7 \%)$ \\
\hline Ophthalmopathy & 2 & 1 \\
\hline Palpitation & $(3.3 \%)$ & $(1.7 \%)$ \\
\hline
\end{tabular}

Table IV: Signs and symptoms related to hyperthyroidism

Two (3.3\%) had enlarged thyroid, tremor in 2 (3.3\%) and palpitation in $13(21.5 \%)$ respectively (Table IV).

\begin{tabular}{ccccc}
\hline \multirow{2}{*}{ beta hCG(mlU/ml) } & \multicolumn{2}{c}{ Hyperthyroidism } & Total & p-value \\
& Present & Absent & & \\
$<100000$ & 1 & 22 & 23 & \\
\hline \multirow{2}{*}{$100000-300000$} & 1 & 28 & 29 & 0.004 \\
& $(1.7 \%)$ & $(36.7 \%)$ & $(13.3 \%)$ & \\
$>300000$ & 4 & 4 & 8 & \\
& $(6.7 \%)$ & $(6.7 \%)$ & $(13.3 \%)$ & \\
Total & 6 & 54 & 60 & \\
& $(10 \%)$ & $(90 \%)$ & $(100 \%)$ &
\end{tabular}

Table V: Level of beta hCG with hyperthyroidism $(n=60)$

High level of beta HCG was seen in 4 (6.7\%) patients with hyperthyroidism and when correlated it was found to be statistically significant (Table V).

\begin{tabular}{|c|c|c|c|c|}
\hline \multirow{2}{*}{$\begin{array}{l}\text { Body mass index } \\
(\mathrm{wt} \text { in } \mathrm{kg} / \mathrm{height} \text { in } \\
\mathrm{m}^{2)}\end{array}$} & \multicolumn{2}{|c|}{ Hyperthyroidism } & \multirow[t]{2}{*}{ Total } & \multirow[t]{4}{*}{$p$-value } \\
\hline & Present & Absent & & \\
\hline \multirow{2}{*}{ Underweight } & 5 & 12 & 17 & \\
\hline & (8.3\%) & $(20 \%)$ & $(28.3 \%)$ & \\
\hline & & 31 & 31 & \multirow{6}{*}{0.005} \\
\hline Normal & 0 & (51.7\%) & (51.75) & \\
\hline \multirow{2}{*}{ Overweight } & 1 & 11 & 12 & \\
\hline & $(1.7 \%)$ & $(18.3 \%)$ & $(20 \%)$ & \\
\hline \multirow{2}{*}{ Total } & 6 & 54 & 60 & \\
\hline & $(10 \%)$ & $(90 \%)$ & $(100 \%)$ & \\
\hline
\end{tabular}

Table VI: Association of body mass index with hyperthyroidism $(n=60)$

The table VI shows distribution of body mass index and their association with hyperthyroidism. Hyperthyroidism was commonly found in patients with molar pregnancy and low BMI with a statistical significance when compared with normal and high BMI patients.

\section{DISCUSSION}

There are wide geographical variations in the prevalence of gestational trophoblastic disease as a result of differences in methodology, case detection and classifications of mole. Hence, comparison of prevalences between countries is often difficult. Prevalence-varies in different part of world. The exact prevalence in Nepal is not known. Malignant potential of this disease is higher in South East Asia where it is found to be as high as $10-15 \%$ in comparison to $2-4 \%$ in Eastern countries. ${ }^{8}$ Prevalence of molar pregnancy at our institution is 5.4 per 1000 pregnancies.

Among the women with molar pregnancy enrolled and evaluated with thyroid function test, hyperthyroidism was present in $6(10 \%)$ cases, which is comparable to the study done by Al-Talib AA, were hyperthyroidism was seen in $4.5 \%$ of molar pregnancies. ${ }^{9}$ In a study by Lakra et al, hyperthyroidism was seen in $4(10.5 \%) .{ }^{10}$ Another study done by Solo et al. on a cohort study done on 60 cases of molar pregnancy reported prevalence of Hyperthyroidism as $13.3 \%$, similar to our study..$^{11}$ Dinesh Kumar et $\mathrm{al}^{12}$ and Dayal et $\mathrm{al}^{13}$ observed $3 \%$ and $5 \%$ of molar pregnancies with hyperthyroidism. Observation in our studies is similar to above studies.

In the present study, maternal age showed statistical significance which was higher in CHM. There was no difference in the gestational age at presentation between the two groups but the pre evacuation beta hCG levels were higher in CHM patients compared to PHM, which was not statistically significant. $10 \%$ of hyperthyroidism seen in CHM whereas no hyperthyroidism in PHM. Mean value of fT3 was higher in (3.91 \pm 1.67$)$ complete mole compared to $(3.211 \pm 0.535)$ partial mole which not statistically significant ( $p$ value 0.171$)$. The value of fT4 $(\mathrm{nmol} / \mathrm{L})$ $1.41 \pm 0.52$ in complete moles and $1.54 \pm 0.422$ in partial moles which is non-significant ( $p$ value 0.970 ). In a similar study done by Harun Dugeroglul and Murat Ozgenoglull ${ }^{14}$ on a crosssectional study, patients with complete mole had higher mean age $(P=0.003)$, higher number of pregnancies $(P=0.032)$, lower TSH values $(P=0.011)$ and higher fT4 and TT4 $(P=0.04$, $P=0.028)$, compared with the patient group with partial mole. The thyroid volume was larger in the complete mole patients $(P=0.032)$, which is comparable to our study.

In the present study, maximum number of patients 20 (33.7\%) belonged to age group $<20,36(60 \%)$ belonged to age group $21-35$ and only $4(6.7 \%)$ belonged to age $>35$ with mean age of 25.08 \pm 8.09 at admission. Similar age group was found in different study done by jethwani et al.in which mean age of having hyperthyroidism in molar pregnancy was 24.68 years, most of the patients (56\%) were in age group of $21-25$ years. ${ }^{15}$ In another study done by Lakra et al. mean age was $23.02 \pm 2.96$ years which is different from our study. ${ }^{10}$ In the present study shows that beta HCG is increased highly in molar pregnancy. 23 (13.3\%) had beta HCG less than 1 lakhs and more than 3 lakhs in $8(13.3 \%)$ patients, whereas $29(46.75 \%)$ had beta HCG in range of 1 lakh to 3 lakhs. Solo et al. on their study mentioned majority of the patients (65\%) had initial $\beta$-hCG>3 Lakhs mIU/ $\mathrm{mL}$, only $3.3 \%$ had $\beta$-hCG value $<1$ lakh $\mathrm{mIU} / \mathrm{mL}$ which is similar 
to our study, the values decreases rapidly with treatment. ${ }^{11}$

$2(3.3 \%)$ had enlarged thyroid, tremor was present in 2 (3.3\%) and palpitation was present in 13 (21.5\%) which is statistically insignificant. Patients having beta hCG level more than three lakh and higher were hyperthyroid $(p=0.004)$. Thyroid storm and thyroid ophthalmopathy was not seen in any of the patients. This is comparable to study conducted by Fantz CR et al. ${ }^{16}$ Majority of patients with hyperthyroidism, 5 (8.3\%) belonged to underweight which is statistically significant $(p=0.005)$. Because of the thyrotropin-like effects of $\beta-h C G$, which cause serum free thyroxine levels to be elevated and TSH levels to be decreased, hyperthyroidism was detected in the study. ${ }^{17}$ During pregnancy, normal thyroid activity undergoes significant changes, hCG has mild thyroid stimulating activity. Hyperthyroidism attributable to GTD should be suspected in patients who demonstrate increased free T4 and T3 concentrations, decreased TSH, and significantly increased HCG. Although free T4 and T3 concentrations can be increased with HCG concentrations.

\section{LIMITATIONS}

This was a tertiary center data; all measurements and results reflect the situation in our center at that time. The available data may not reflect the true prevalence in the population. Limitation of our study includes limited follow-up for some of these patients, which as noted, would remain a continuous ongoing challenge for the tertiary care hospital.

\section{CONCLUSION}

Hospital prevalence of molar pregnancy is high. Association of hyperthyroidism with this condition is not uncommon. Thyroid function test is a reliable indicator of hyperthyroidism. The risk of hyperthyroidism in molar pregnancy is associated with maternal age, complete hydatiform mole, high level beta HCG and low BMI.

\section{REFERENCES}

1. Lybol C, Thomas CMG, Bulten J, et al. Increase in the incidence of gestational trophoblastic disease in the Netherlands. Gynecol Oncol 2011;121(2):334-8.

2. Lurain JR. Gestational trophoblastic disease I: Epidemiology, pathology, clinical presentation and diagnosis of gestational trophoblastic disease, and management of hydatidiform mole. Am J Obstet Gynecol. 2010;203(6):531-9.

3. Koirala A, Khatiwada P, Giri A, et al. The demographics of molar pregnancies in BPKIHS. Kathmandu Univ Med J. 2011;9(36):298-300.

4. Agrawal N, Sagtani RA, Budhathoki SS, et al. Clinicoepidemiological profile of molar pregnancies in a tertiary care centre of Eastern Nepal: a retrospective review of medical records. Gynecol Oncol Res Pract. 2015;2(9):1-7.

5. JarettVanz-Brian Pereira, Taylor Lim .Hyperthyroidism in gestational trophoblastic disease - a literature review.
Thyroid Res 2021 Jan 14;14(1):1.

6. Nandini D, Sarita F, Uday A, et al. Hydatidiform mole with hyperthyroidism - perioperative challenges. J Obstet Gynecol India. 2009;59(4):356-7.

7. Virmani S. Transient Thyrotoxicosis in Molar Pregnancy J Clin Diagnostic Res. 2017;11(7): QD01-Qd02. Published online 2017 Jul 1. Doi: 10.7860/JCDR/2017/28561.10133.

8. Pariyar J, Shrestha B, Shrestha J, et al. Gestational Trophoblastic Disease: Review of Cases Managed at BP Koirala Memorial Cancer Hospital. Nepal J Obstet Gynaecol. 2013;8(1):18-21.

9. Al-Talib AA. Clinical presentation and treatment outcome of molar pregnancy: Ten years' experience at a Tertiary Care Hospital in Dammam, Saudi Arabia - J Fam Community Med 2230-8229;2016;23:161-165.

10. Lakra P, Sangwan V, Siwach S, et al. Outcome of gestational trophoblastic disease in a rural tertiary centre of Haryana, India. Int J Reprod Contraception, Obstet Gynecol. 2016;6(1):271.

11. Solo VE, Tamphasana A, Laishram G, et al. A Clinical Study of Hydatidiform Mole. 2019;18(7):15-9.

12. Kumar D, Singh YA, Kumar Singh LS, et al. A Study of Molar Pregnancy at Tertiary Centre of India. IOSR J Dent Med Sci. 2016;15(09):49-52.

13. Dayal S, Negi S, Singh A, et al. Audit of partial and complete hydatidiform moles in tertiary care hospital in rural inhabitants of India. Indian J Heal Sci. 2014;7(2):104.

14. Dugeroglul H, Özgenoğlull $M$. Thyroid function among women with gestational trophoblastic diseases. A crosssectional study. Sao Paulo Med J. 2019;137(3):278-83.

15. Dr Lovely Jethwani, Dr Rekha Choudhary, Dr Indra Bhati, et al. Clinico-epidemiological profile of molar pregnancies at a tertiary care centre of India : A prospective observational study Gynecology : 2017;(7):45-8.

16. Fantz CR, Dagogo-Jack S, Ladenson JH, et al. Thyroid function during pregnancy. Clin Chem. 1999; 45(12) :2250-8.

17. Nagataki S, Mizuno M, Sakamoto $S$, et al. Thyroid function in molar pregnancy. J Clin Endocrinol Metab. 1977; 44(2):25463.

18. Cunningham FG, Leveno $\mathrm{KJ}$, Bloom SL, et al. Williams Obstetrics.25th edition. New York, McGraw Hill .2018. page. 1258. 